\title{
Method development and validation of clobazam in bulk and pharmaceutical dosage forms by using high performance thin layer chromatographic method
}

\author{
Chaithra. R. ${ }^{1}$, Senthil Kumar. G. P. ${ }^{1}$, Poojashree. P. ${ }^{1}$, Vidya. D. N. ${ }^{1}$, Bhadresh. D. R. ${ }^{1}$, Manojkumar. S. ${ }^{1}$ \\ ${ }^{I}$ Department of Pharmaceutical Chemistry, Bharathi College of Pharmacy, Bharathinagara, \\ Tal-Madhur, Dist.- Mandya, Karnataka, 571422, India \\ *Corresponding author E-mail: drsenn78@yahoo.com
}

\begin{abstract}
In the present research a simple, accurate, precise and cost-effective High-performance thin layer chromatographic method for the estimation of clobazam, in bulk and pharmaceutical dosage form was illustrated. The RF value of the drug was found to be 0.74 in the mobile phase, acetone: toluene: formic acid (1: 1: $0.05 \mathrm{v} / \mathrm{v} / \mathrm{v})$. A linear response was observed in the range of 100-700 ng with a regression coefficient of 0.999. Validation parameters were carried out as per the guidelines of International Conference for Harmonization (ICH). This method can be used in the industries for determination of clobazam to analyze the quality of formulation without interference of the excipients.
\end{abstract}

Keywords: Clobazam; Anti-Epileptic; $\lambda$ max; ICH; High Performance Thin Layer Chromatography.

\section{Introduction}

Clobazam is an antiepileptic drug belonging to the benzodiazepine series coming under the class of Anticonvulsant drugs and chemically called as 7-chloro-1,5-dihydro-1-methyl-5-phenyl-1,5-benzodiazepine2,4(3H)-dione (Fig 1). Clobazam is a long-acting 1,5-benzodiazepine with uses similar to those of diazepam as 1,4-benzodiazepine. It is used in the treatment of epilepsy in association with other antiepileptics. It is also used in the short-term treatment of acute anxiety [1-2]. Clobazam belongs to the 1,5-benzodiazepine class with a pka value of 6.65. Clobazam bulk powder is a white crystal with molecular weight of 300.7. the drug is slightly soluble in water and soluble in organic solvents [3]. The reference of Clobazam is not found in majority of pharmaceutical and chemistry books. clobazam is official in British and Indian pharmacopoeia 2007 [4-5]. Today majority of marketed antiepileptic dosage forms are of clobazam e.g. Frisium, Urbanyl, etc., There are several research papers which illustrates the method for estimation of clobazam by colorimetry and HPLC in bulk and pharmaceutical dosage form [6-7]. Also, there are several bio-analytical methods developed for clobazam in biological fluids containing clobazam, like serum and plasma [8]. There have been very a smaller number of analytical methods developed for estimation of clobazam in pure bulk form and in dosage form. In the present study method development and validation was carried out by HPTLC method [9].

7-chloro-1-methyl-5-phenyl-1H-1,5-benzodiazepine-2,4(3H,5H)-dione<smiles>CN1C(=O)CC(=O)N(c2ccccc2)c2cc(Cl)ccc21</smiles>

Fig. 1: Structure of Clobazam 


\section{Experimental}

\subsection{Chemicals}

Clobazam was obtained from Sanofi-Aventis, Ltd. Goa, India. Acetone, toluene and formic acid were purchased from Qualigens fine chemicals, India. Chemicals and reagents were of AR-grade.

\subsection{Chromatography}

Analysis was performed on $10 \times 10 \mathrm{~cm}$ aluminium backed silica gel F254 HPTLC plates (E-Merck, Darmstadt, Germany). Before using, the plates were predeveloped with methanol and then dried in an oven at $60{ }^{\circ} \mathrm{C}$ for $5 \mathrm{~min}$. Standard solution and sample solution were applied to the plate as $6 \mathrm{~mm}$ bands by means of a Camag Linomat-V (Muttenz, Switzerland) sample applicator equipped with $100 \mu \mathrm{l}$ syringe (Hamilton, Reno, Nevada, USA); the distance between the bands was $11.6 \mathrm{~mm}$. Camag twin trough chamber used as development chamber previously saturated for 20 min with acetone: toluene: formic acid (1: 1: $0.05 \mathrm{v} / \mathrm{v} / \mathrm{v}$ ) as mobile phase. The average development time is $20 \mathrm{~min}$. After development, the plate was dried at $110{ }^{\circ} \mathrm{C}$ in an oven for $10 \mathrm{~min}$. Densitometric scanning at $254 \mathrm{~nm}$ was then performed with a Camag TLC Scanner equipped with Win-Cat software, version 1.3.0 using a Deuterium light source. The slit dimensions were $6.00 \mathrm{~mm} \times 0.20 \mathrm{~mm}$.

\subsection{Optimization and detection of UV wavelength}

The sensitivity of HPTLC method that uses UV/VIS detection depends upon the proper selection of detection wavelength. An ideal wavelength is one that gives good response for the drug that is to be analyzed. In the present study, by appropriate dilution of each stock solution, various concentrations of clobazam were prepared. Each solution was scanned in the spectrum mode and their spectra were observed. The wavelength selected for the analysis was $254 \mathrm{~nm}$ at which clobazam showed significance absorbance.

\subsection{Preparation of stock solutions}

Standard clobazam $10 \mathrm{mg}$ was weighed and transferred to a $10 \mathrm{ml}$ volumetric flask. $5 \mathrm{ml}$ of methanol was added to dissolve the drug. The flask was shaken and volume was made up to the mark with methanol to give a solution containing concentration of $1000 \mu \mathrm{g} / \mathrm{ml}$ ( solution A). From this stock solution, pipette out $1 \mathrm{ml}$ and place it in $10 \mathrm{ml}$ volumetric flask. The volume was made up to mark with methanol to give a solution containing concentration of $100 \mu \mathrm{g} / \mathrm{ml}$ (stock solution B).

\subsection{Method validation $[10]$}

\subsubsection{Linearity}

Standard solution equivalent to 100, 200, 300, 400, 500, 600 and $700 \mathrm{ng}$ per band of clobazam were applied to a pre-developed HPTLC plate. The plate was developed, dried and scanned as described above. The chromatograms were obtained and peak area was determined for each concentrations of drug solution. A calibration plot was constructed by plotting peak area against amount of clobazam (ng). The linearity of response for clobazam was assessed in the concentration ranges 100-700 ng per band; the slope, intercept, and correlation coefficient were also determined.

\subsubsection{Limit of detection (LOD) and limit of quantitation (LOQ)}

The limit of detection (LOD) and limit of quantitation of clobazam were determined by using standard deviation of the response and slope approach as defined as in International Conference on Harmonization (ICH) guidelines.

The LOD and LOQ were calculated by using following formulae

LOD $=3.3 \times$ S.D of intercept/ Average of slope.

LOQ $=10 \times$ S.D of intercept $/$ Average of slope.

\subsubsection{Precision}

Precision was evaluated by using standard solutions containing clobazam at concentration covering the 100, 200 and $300 \mathrm{ng}$ per band. The precision of the method in terms of intra-day precision (\% R.S.D) was determined by analyzing clobazam standard solution in the range (100-300 ng per band) three times on the same day. The inter-day precision (\% R.S.D) was assessed by analyzing these solutions (100-300 ng per band) on three different days over a period of one week.

\subsubsection{Accuracy}

Accuracy is the closeness of the test results obtained by the method to the true value. To study the Accuracy, twenty tablets of each formulation were weighed and powdered and also analysis of the same was carried out. Recovery studies were carried out using standard addition method by adding known amount of standard drug solution $(50 \%, 100 \%$ and $150 \%)$ to the sample solution and \% recovery was calculated.

\subsubsection{Reproducibility}

The reproducibility of sample application was assessed by spotting drug solution (4 $\mu 1)$ six times on a HPTLC plate, then development of plate and recording the peak AUC. 


\subsection{Analysis of the marketed formulation}

Twenty tablets [Frisium 5, Sanofi-Aventis, Ltd.] were weighed and finely powdered. The powder equivalent to $10 \mathrm{mg}$ of clobazam was accurately weighed and transferred to $10 \mathrm{ml}$ volumetric flask containing $5 \mathrm{ml}$ methanol. The flask was shaken and volume was made up to the mark with methanol. The solution was filtered through Whatmann filter paper (No. 41) to give a solution of concentration $1000 \mu \mathrm{g} / \mathrm{ml}$. From the above solution pipette out $1 \mathrm{ml}$ and make up the volume to $10 \mathrm{ml}$ with methanol to give a solution containing $100 \mu \mathrm{g} / \mathrm{ml}$. From this solution, appropriate volume was injected to the TLC plate. The analysis was carried out by two analysts.

\section{Results and discussion}

\subsection{Optimization of the procedure}

The pure drug was applied to the TLC plates and chromatographed with different mobile phases. Initially ethyl acetate: chloroform (4: 6 $\mathrm{v} / \mathrm{v})$ and acetone: toluene $(1: 1 \mathrm{v} / \mathrm{v})$ were tried. Addition of $0.05 \mathrm{ml}$ formic acid to these mobile phases improved the characteristics of the bands. Finally, the mobile phase acetone: toluene: formic acid (1: $1: 0.05 \mathrm{v} / \mathrm{v} / \mathrm{v})$ was found to enable good resolution with a sharp and symmetrical peak of $R_{F} 0.74$. Well defined bands were obtained when the chamber was saturated with mobile phase for 20 min at room temperature (Fig.2)

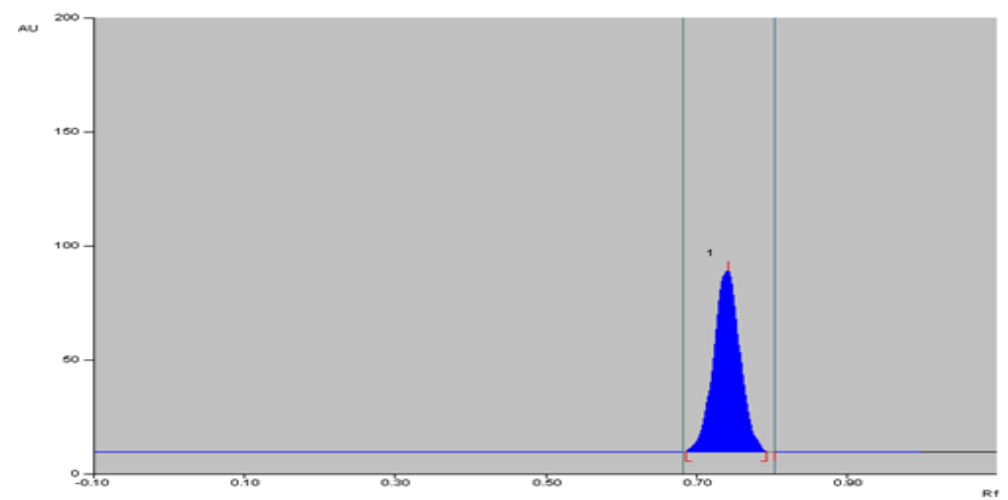

Fig. 2: Densitogram Obtained from Clobazam Standard by HPTLC Method.

\subsubsection{Linearity}

The calibration graph was linear, i.e. the system adhered to Beer's law, over the range 100-700 ng per band. Linearity was evaluated by duplicate analysis of seven standard working solutions equivalent to 100-700 ng per band of clobazam. The regression data showed linearity was good over the concentration range investigated; this was apparent from the high value of the correlation coefficient. Typical linearity data are given in Table 1.

The calibration curve (Fig. 3) and 3D view (Fig. 4) shows good correlation between clobazam concentrations and peak areas (Fig. 5).

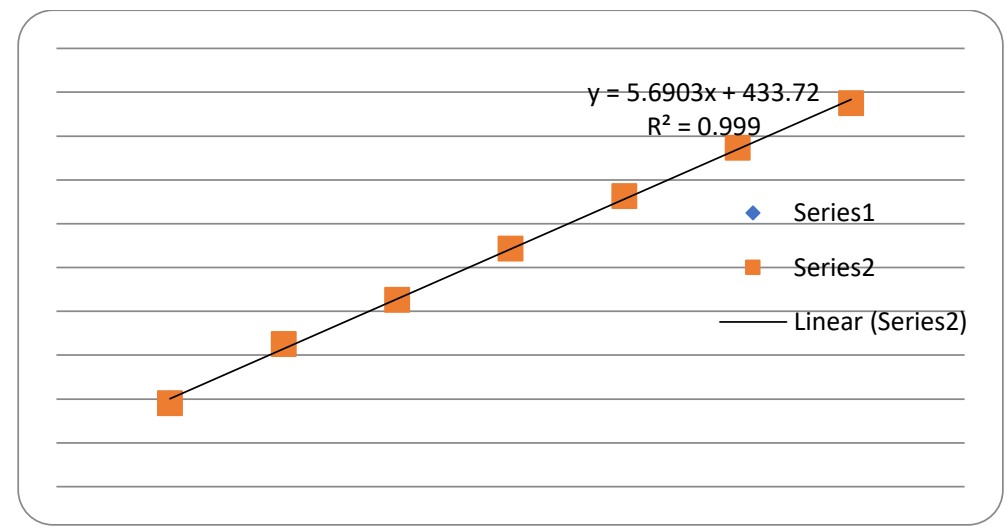

Fig. 3: Calibration Curve of Clobazam by HPTLC Method. 


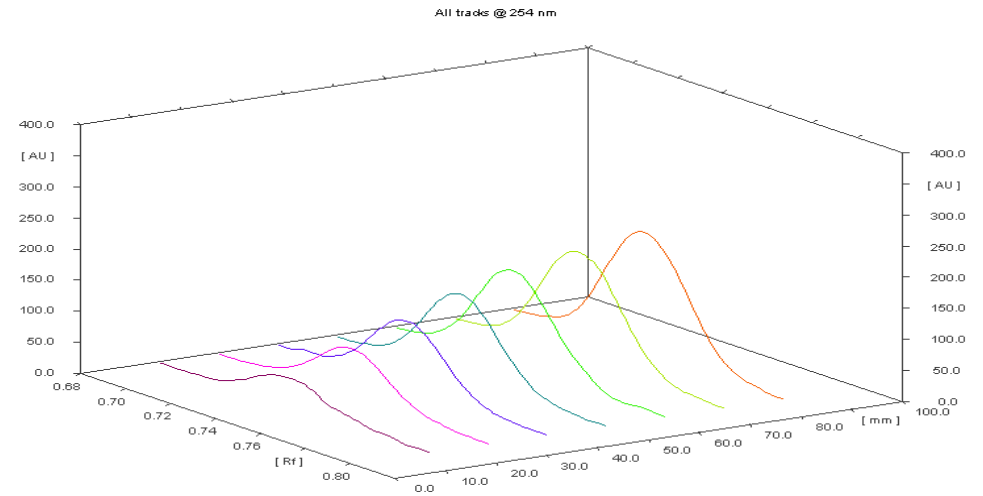

Fig. 4: 3D View of Clobazam by HPTLC Method.

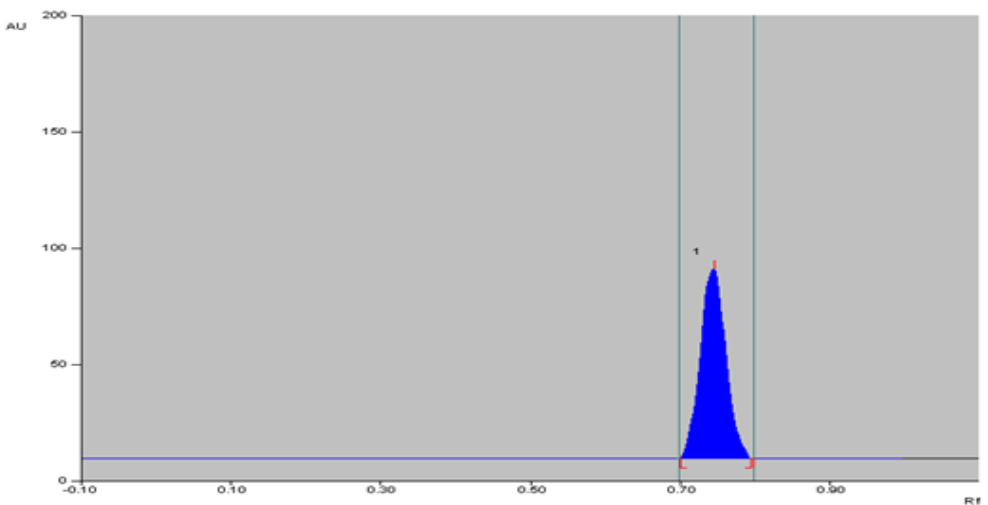

Fig. 5: Chromatogram of 400ng of Sample Solution of Clobazam by HPTLC Method.

Table 1: Linear Regression Data for the Calibration Plots

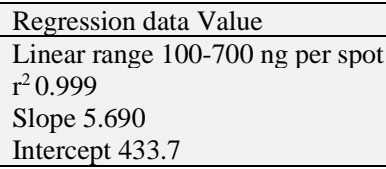

\subsubsection{Limit of detection (LOD) and limit of quantification (LOQ)}

LOD and LOQ for the proposed method were found to be 20.98 and $63.56 \mathrm{ng}$ per band, respectively.

\subsubsection{Precision}

Repeatability of sample application of peak area, as \% R.S.D, was determined for concentrations 100, 200 and 300 ng. \% R.S.D for interday and intraday analysis was $<2 \%$. The values are shown in Table 2.

Table 2: Results of the Measurement of Intra and Interlay Precision for Clobazam by HPTLC Method

\begin{tabular}{lllll}
\hline Concentration (ng per spot) & Intra-day precision Mean \pm S. D** & \% R. S. D & Inter-day Precision Mean \pm S. D** & $\%$ R. S. D \\
\hline 100 & $943.3 \pm 15.42$ & 1.635 & $945.26 \pm 0.66$ & 0.070 \\
200 & $1618.6 \pm 9.77$ & 0.639 & $1658 \pm 17.74$ & 0.949 \\
300 & $2199.3 \pm 24.54$ & 1.116 & $2215.4 \pm 40.61$ & 1.833 \\
\hline
\end{tabular}

**Average of Three determinations.

\subsubsection{Accuracy}

When the method was used for subsequent analysis of clobazam in Pharmaceutical dosage form spiked with 50, 1001 nd $150 \%$ extra drug, recovery was $98-102 \%$ of clobazam as bulk and in dosage form (Table 3 ).

Table 3: Results of Accuracy Studies of Clobazam by HPTLC Method

\begin{tabular}{llll}
\hline Level of recovery $(\%)$ & Amount of drug added $(\mathrm{mg})$ & Amount of drug recovered $(\mathrm{mg}) *$ & $\%$ Recovery \pm S. D* \\
\hline 50 & 5 & 5.05 & $101.92 \pm 0.479$ \\
100 & 10 & 9.95 & $99.55 \pm 0.286$ \\
150 & 15 & 14.80 & $98.68 \pm 0.917$ \\
\hline
\end{tabular}

*Average of three determinations

\subsubsection{Reproducibility}

The \% R.S.D was calculated for peak area and $\mathrm{R}_{\mathrm{F}}$ value with repeated determination for the same concentration. The studies were carried out using $400 \mathrm{ng}$ as a target concentration. The reports are listed in Table 4. 
Table 4: Reproducibility Results of Clobazam by HPTLC Method

\begin{tabular}{|c|c|c|}
\hline S1. No & Area & $\mathrm{Rf}$ \\
\hline 1 & 2749.8 & 0.74 \\
\hline 2 & 2780.8 & 0.75 \\
\hline 3 & 32734 & 0.74 \\
\hline 4 & 2822.8 & 0.74 \\
\hline 5 & 2839.8 & 0.74 \\
\hline 6 & 2829.4 & 0.75 \\
\hline Mean & 2792 & 0.74 \\
\hline S. D & 44.49 & 0.0051 \\
\hline \% R.S. D & 1.593 & 0.6947 \\
\hline
\end{tabular}

\subsection{Analysis of marketed formulation}

A single band at $\mathrm{R}_{\mathrm{F}} 0.74$ was observed in the densitogram of drug samples extracted from tablets. There was no interference from excipients commonly present in the tablets. The drug content was found to be $99.84 \%$ and 99.44 for analyst 1 and analyst 2 , respectively. The results are reported in Table 5.

Table 5: Applicability of the Proposed HPTLC Method for Analysis of Commercial Tablets

\begin{tabular}{llllll}
\hline Sample & Label claim $(\mathrm{mg})$ & $\begin{array}{l}\text { Analyst I } \\
\text { Amount found }(\mathrm{mg})\end{array}$ & \% Recovery \pm S.D $* *$ & $\begin{array}{l}\text { Analyst II } \\
\text { Amount found (mg) }\end{array}$ & $\%$ Recovery \pm S.D** \\
\hline Frisium & 5 & 4.99 & $99.84 \pm 1.04$ & 4.97 & $99.44 \pm 1.271$ \\
\hline **Average of three determinations & &
\end{tabular}

\section{Conclusion}

This HPTLC method for quantitative analysis of clobazam in Pharmaceutical formulations is cost effective, precise, accurate and reproducible without interference from the excipients. The method was validated in accordance with ICH guidelines. The method reduces analysis time compared with other methods and seems to be suitable for routine analysis of Pharmaceutical formulations in quality-control laboratories, where economy and speed are essential.

\section{Acknowledgement}

Authors wish to thank the Principal, Bharathi College of pharmacy, Bharathinagar for providing the facilities to carry out the research work.

\section{References}

[1] Senthilkumar, G. P., Parag, S, Mahadik., Parthiban, S., Tamizhmani, T., 2016. Method development and validation of clobazam in bulk and pharmaceutical dosage forms by using RP-HPLC Method. Am. J. Pharm Tech Res. 6, 624-31.

[2] Jat, R. K., Sharma, R. C., 2011. Research Article Quantitative Estimation of Clobazam in Bulk drug and tablets. IJCPR. 1, $19-24$.

[3] Effat Souri., Amin Dastjani Farahani., Reza Ahmadkhaniha., Mohsen Amini., 2014. A stability indicating HPLC method for the determination of clobazam and its basic degradation product characterization. DARU Journal of pharmaceutical sciences. 22, 02-07. https://doi.org/10.1186/20082231-22-49.

[4] Indian Pharmacopoeia, 5th edition, Indian Pharmacopoeia Commission, Gagiabad, India 2007(2), 945-47.

[5] British Pharmacopoeia, 13th edition Stationary office on behalf of Medicine and Healthcare Products Regulatory agency, London, UK 2009(1), 373.

[6] Abounassif, M. A., Kariem, E. R., Aboul-Enein, H, Y., 1987. High-performance liquid chromatographic determination of clobazam and one of its pharmaceutical formulations. Journal of pharmaceutical and biomedical analysis. 4, 431-34. https://doi.org/10.1016/0731-7085(87)80051-1.

[7] Pok, P. R., Mauras, M., De Saint Léger, M. N., Kuhlmann, E., Charpenel-Durat, C., Navarette, C., Duval, M. L., De Meo, P., 2010. Blood concentrations of clobazam and norclobazam in a lethal case involving clobazam, meprobamate and clorazepate. Legal Medicine. 12, 300-4. https://doi.org/10.1016/j.legalmed.2010.08.002.

[8] Peña, M, I., Lope, E, S., 1988. Monitoring serum clobazam by isothermal gas-liquid chromatography with nitrogen detector. Journal of pharmaceutical and biomedical analysis. 6, 995-8. https://doi.org/10.1016/0731-7085(88)80122-5.

[9] Gharge, D., Salve, P., Raut, C., Seervi, C., Pawar, K., Dhabale, P., 2010. Validated Spectroscopic Method for Estimation of Aceclofenac from Tablet Formulation. Tablet. 1(100mg), 100-2.

[10] International Conference on Harmonization (ICH) of Technical Requirements for Registration of Pharmaceuticals for Human Use: Harmonized Triplicate Guideline on Validation of analytical Procedures: Methodology, Recommended for Adoption at Step 4 of the ICH Process on November 1996 by ICH Steering Committee, IFPMA, Switzerland. 